American Journal of Applied Sciences 7 (2): 160-166, 2010

ISSN 1546-9239

(C) 2010 Science Publications

\title{
Development of A Semi-Industrial Multi Fruit Dryer System Using Simultaneous Intelligent Control
}

\author{
${ }^{1}$ Marjan Javanmard, ${ }^{1}$ Johari Endan, ${ }^{2}$ K.A. Abbas and ${ }^{3}$ Farshad Arvin \\ ${ }^{1}$ Department of Process and Food Engineering, Faculty of Engineering, \\ University of Putra Malaysia, 43400 UPM, Serdang, Selangor, Malaysia \\ ${ }^{2}$ Department of Food Technology, Faculty of Food Science and Technology, \\ University of Putra Malaysia, 43400 UPM, Serdang, Selangor, Malaysia \\ ${ }^{3}$ Department of Computer System Engineering, Faculty of Engineering, \\ University of Putra Malaysia, 43400 UPM, Serdang, Selangor, Malaysia
}

\begin{abstract}
Problem statement: This study presented a semi-industrial fruit dryer machine which is useful to dry different types of fruit. The drying process and its functions are selectable by user to obtain a multi dryer system. Approach: A microcontroller base controller that enables to simultaneous monitoring was utilized. There are two types of sensors as the inputs of system which are temperature and humidity. The output of sensors continuously was monitored with the main processor and given functions based on fruit types are executed. The selected fruits were put on trays in batch dryer. Results: Presented system was tested on three different fruits which have differences in texture and moisture content. The optimum drying temperature where provided because the product would be dried without burning. The material moisture content decreased throughout the drying process. A cause study was done to illustrate the effectiveness of the designed dryer. Conclusion: Several performed results illustrated the amenability of proposed system as the multi-fruit dryer machine.
\end{abstract}

Key words: Fruit dryer, batch, moisture, microcontroller

\section{INTRODUCTION}

Drying has been used centuries as a method for food preservation. Fluid extraction in material is known as drying by this means that water is removed from solids to a certain level with different techniques (Barrett et al., 2005). Hence drying is moisture migration from material in a specific period of time. The drying system is the factors that influence drying such as the moisture content of the material that is intended to be dried, the heating temperature (Ceylan et al., 2007).

In Dehydration operations there are two stages of moisture loss first the phase that water is evaporated and then the evaporated water will be extracted. Therefore drying is important for chemical and food processing. Throughout the drying procedure high energy levels are consumed this is because of moisture removal from the body this fact makes drying operations high energy procedures (Teeboonma et al., 2002; Ivanova and Andonov, 2001).

Drying characteristics of fruits depends on various factors such as sorption equilibrium, density and thermal properties design of any kind of heating process required knowledge about the materials density and thermal attributes, shrinkage since during drying changes will appear in volume and internal porosity these changes will lead to changes in shape and size of the final product, mass transfer and dielectric properties (Ceylan et al., 2007; Carsky, 2008).

Generally the air drying curves are composed of two periods the first phase is constant rate that free water is evaporated this period is controlled by the heat given to the material and mass transfer rates thus mainly the boundary layer is responsible for the transport mechanism (Barrett et al., 2005). The second part is the falling rate that is known to be complicated phenomena because the controlling factor is the transport resistance within the particles to be dried. Consequently, both exterior and interior conditions are influential on the drying process.

Fresh fruit waste and increasing demand for dries fruits has made a new initiative for food manufactures to produce dried fruit products (Desmorieux et al., 2008).

Corresponding Author: Marjan Javanmard, Department of Process and Food Engineering, Faculty of Engineering, University of Putra Malaysia, 43400 UPM, Serdang, Selangor, Malaysia 
In order to reduce the moisture content there are a number of dryer found. Batch fruit tray dryer with hot air flow has been widely used among other techniques of drying (Kiranoudis et al., 1997). This drying method is based on hot air transportation through the trays which material lies on. Higher circulation rates result in high rates of heat and mass transfer from the body although increasing the temperature will have a direct effect on the quality parameters such as color, shape, texture and nutrient components (Das et al., 2001).

To obtain higher quality products, reliable controller is the significant requirement. There are several types of controllers which are utilized in industrial automations. The common controllers are Programmable Logic Controller (PLC) which various developers commercialized. The performance of PLC as the industrial grade controller has been illustrated. The total cost of PLC-based automation is very expensive and does not allow using in small systems. Microcontroller is the other processor component which is very low-cost processor. It is being employed in many semi-industrial projects and small factories. In developed system, we used ATMEGA-32 microcontroller that is high performance and low-cost component.

When studying the economics of utilization of electrical heater and gas heater it was recommended that although the cost of the electrical heater was higher but it was more economical (Chua and Chou, 2003). The objective of this research were to investigate the drying conditions and show the design of an industrial low cost and energy efficient batch fruit tray drier based on pilot plant experiments.

\section{MATERIALS AND METHODS}

Historically, artificial fruit drying has been originated as an important method to preserve fruits in the off-season. On the other hand, drying may change the initial physical form of fruit for example change in color, texture, and taste. The main reaction in drying process is the water loss which leads to reduction in water activity. This procedure can extend the shelf life of the product (Nijhuis et al., 1998).

Fruits are dried in three methods, the whole fruit can be dried for instance in apricot second method is when the fruit is sliced like in banana, mango, papaya and the last one is dried into powder form such as pastes (Soponronnsrit et al., 1997). The type of the dryer employed for drying is completely dependent to the physical properties of the fruit. For whole drying the sun dryers or air circulation dryer are usually used for sliced fruit tray dryers, freeze dryers, and conveyer.
For paste drying, spray and drum dryers are utilized (Ivanova and Andonov, 2001).

In fruit dehydration there are some factors that affect the final products quality therefore for selection of the method of drying these factors should be taken into account; very high initial moisture contents, sensitivity to high temperatures, high sugar content, high risk for microbial attack (Umesh et al., 2004).

Drying process: Drying is an energy consuming process that results in evaporation of the water of the fruit body and removal of the moisture content. In hot air dryers the heat required for the drying process is supplied by hot air which cycles through the dryer and contacts the product in our case fruit (Wang et al., 2007; Lewicki, 2006). The fruit dryer designed is a cabinet type drier and basically batch type equipment. The trays are rectangular shape with the dimension of $40 \times 40 \mathrm{~cm}$. The fruit dryer was tunnel shape and constructed of stainless steel with an area of $0.5 \times 1 \times 1.5 \mathrm{~m}$. The dryer consists of a heating control unit which supplies the drying energy by an electrical heater, an electrical fan that creates forced flow of hot air through the trays, measuring sensors and the chamber which has been discussed earlier. The operation can be controlled which this part will be discussed further. The drying hot air was achieved by the electrical heating and controlled by the heating control unit. The air which was heated to the desired temperature then enters the drying chamber as shown in Fig. 1. The air temperature can be altered by the temperature controller. Furthermore the air flow rate was varied by utilizing the speed controller of the fans and moreover by adjusting dampers in the dryer design. The air velocity was controlled at approximately $2 \mathrm{~cm}$ above the surface of the trays. The drier proposed in this study is manufactured with sixteen trays in each wagon as shown in Fig. 2. As said before dryer is energy consuming equipment due to requiring electrical energy. The electrical energy is diverse into heat which increases the air temperature in contact with food stuff and dries them. Although energy consumption is secondary consideration compared with quality in most of the fruit dryer designs.

Fruit used: In the batch fruit dryer proposed there were three types of fruits that the pilot plant experiments were performed on to get the results of the device. Apple slices were tested with the dryer. Since dried apples are common snacks and are easily handled and stored and if the storage conditions are suitable the dried apples can be held for a long time without getting spoiled (Velic et al., 2004). 


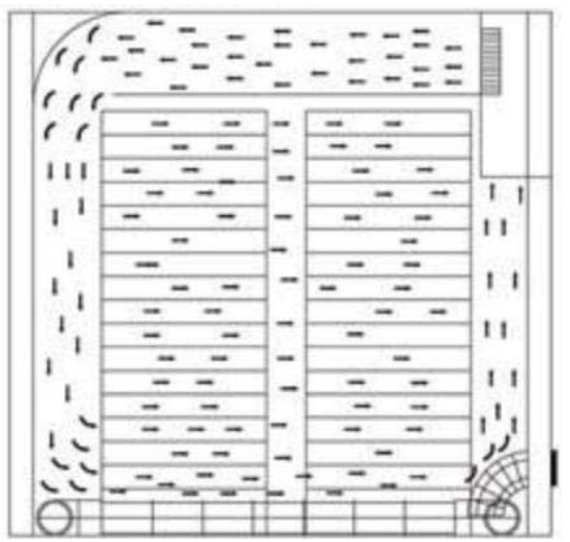

Fig. 1: Hot air circulation between the trays

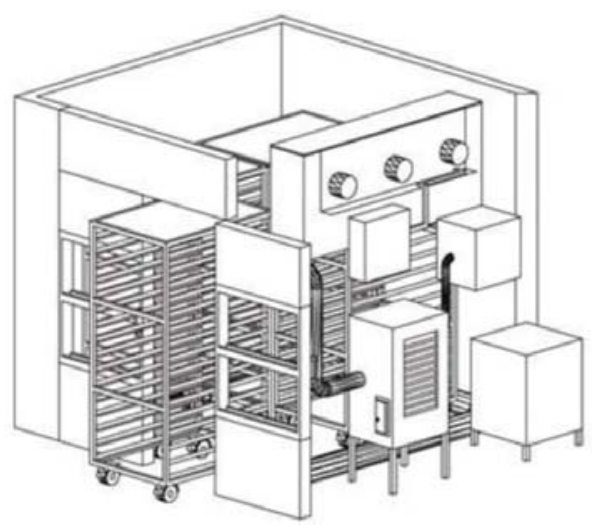

Fig. 2: The designed fruit dryer machine

One of the important facts is the size of the apple slices moreover because of the change of color in dried apple products they should be treated with sulfur dioxide prior to the drying process. For apples the mean moisture content should be approximately 22\% (Lewicki and Jakubczyk, 2004). Other experiments were done on banana. Dehydrated banana products are in two kinds the first one is preformed with drum drier which is called banana flakes and the other one is done with hot air circulation that is termed as banana fig. Banana figs were originally dried by sun but costumer demand made the producers to use hot air for drying. Sulfurous acid solutions are added to banana as well (Soponronnsrit et al., 1997; Karim and Hawlader, 2005; Maskan, 2000). Dried plums or in other words prunes are well known among the fruits since most of the plums are dried until the moisture content reaches between 19-35\% (Doymaz, 2004). Apple, banana and prune where experimented in the batch fruit drier designed and the results are further discussed.

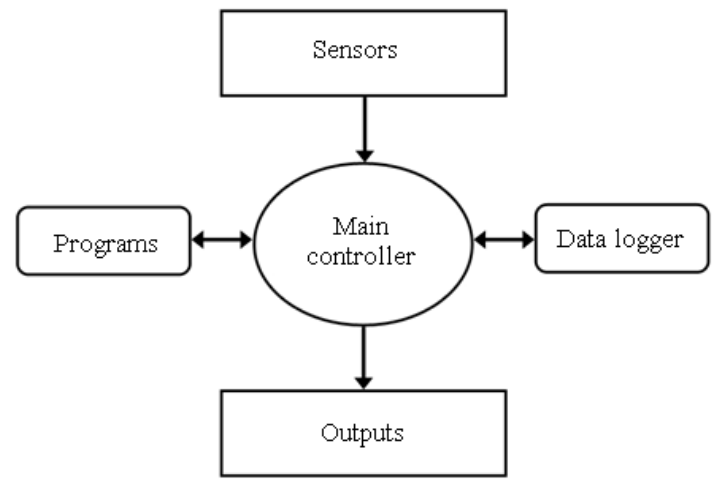

Fig. 3: Important modules of proposed design

Experimental material: The samples were obtained from the local market washed and sliced (fruit slices were prepared by first peeling and then peeling the skin off) into the desired size for each fruit. Then the specimens were spread uniformly in a single layer on the stainless steel trays. Before starting the experiment the dryer was adjusted half an hour to reach steady state condition at the required temperature depending to the selected fruit. After confirming that the dryer condition is in steady state the trays were placed in the drying chamber. The door of the chamber was sealed to make sure there was no escape of the hot air. The temperature and the air velocity was different depending to the specimen although the direction of the air flow for all samples was perpendicular to the fruits laid on the tray. The tests were done twice and the average of the moisture ratios was used for drawing the drying curves.

Controller unit: The significant unit in intelligent systems is the controller unit which allows defining complex applications and also implementing practical interface. There are several types of controllers which are being used in various engineering processes. The cost efficient of controllers is an important issue in decision of systems' configuration. Commonly each controller-based system includes three modules: (i) sensory system, (ii) main controller and (iii) outputs. Also, to achieve intelligent system we need to record past system's events as data logger. Theses data will assist to obtain suitable decision for next time duration. There are different drying processes for various genres of fruits. Each fruit has own drying time duration and control table. So, to obtain multi application system, a flexible interface is required to import different drying tables. Tables include controlling signals in time intervals. In following section, the modules of proposed controller will be discussed. Figure 3 shows five important modules of this system. 
Sensory system: Sensors have a significant function in environmental controlling systems. Achieving to suitable system and amenable process will not be possible without any enough perception of physical environment. Sensors are common components for converting physical characteristics to electrical values. Recently, different types of sensors were produced and there are hundreds companies which commercialized thousands sensors with various functions and quality.

In drying machines, two types of sensors are utilized for recording humidity and temperature of cabin. In fact, drying process is not more than an appropriate control on humidity and temperature of materials according to their properties. Proper process results to best product without more changes in shape, color and tastes.

In food industry machines, two temperature sensors in different situations are used for calculating relative humidity. In this technique, one of sensors placed on wet bulb and other one is in dry bulb. The Wet Bulb temperature is the temperature that is indicated by a moistened thermometer bulb exposed to the air flow $\left(4.6 \mathrm{~m} \mathrm{sec}^{-1}\right)$. The Dry Bulb temperature refers to the surrounding air temperature. It is called Dry Bulb because the air temperature is indicated by a thermometer that is not affected by the moisture of the air (Javanmard et al., 2009). In our dryer this technique was employed to calculate relative humidity of cabin and also additional humidity sensors are placed in some parts of cabin to average cabin's humidity extraction.

Outputs of sensors are analog voltage levels so need to convert to digital value to feed processing unit. Sixteen temperature sensors are employed which are placed in each trays' bed. Three temperature sensors are placed in down, middle and top levels of cabin as wet bulb sensors. With using different levels of sensor, we can monitor whole cabin's status simultaneously to decide suitable control. Outputs of sensors converted to 10 bit digital values which are between 0 and 1023. The analog multiplexer are utilized because of sensors number which are more than converter's inputs. Therefore, sensors are connected to selectable multiplexers' inputs and controller can select an input channel in a time interval. Main controller uses pulling technique for capturing data. Figure 4 illustrates sensory system and its architecture.

The Analog to Digital Converter (ADC) has eight individual channels which are able to produce digital value less than microsecond interval. Multiplexers give us an opportunity to connect large number sensors more than converter number. The specified input will be selected using $\mathrm{S}_{0-2}$ for first multiplexer and $\mathrm{S}_{3-5}$ for second multiplexer. When an input is selected for capturing process, several converted values of given input will be recorded. Final digital value is the average of total captured values. For selecting an input for capturing, a binary value as a selection signal will be put with main processing unit.

The wet bulb and also the humidity sensors are connected to ADC inputs directly. The average function is utilized to obtain true input.

Control equipments: The outputs of system include several various equipments which operate as the control of system's physical status. The output equipments are listed as Table 1. There are several types of control for controlling physical environments. Configuration of equipments will be discussed in system design section. Pulse-Width Modulation (PWM) is a popular technique for controlling output voltage which is feasible approach in motors' speed control (Erikson and Dragan, 2001). When different speed of fan is required the PWM approach will assist us. It uses duty-cycle principle and average voltage for controlling fan speed smoothly. We can have different speed levels between 0 and $100 \%$ of maximum speed (Valentine, 1998). The other technique to output control is binary signal which has two states, on or off. If a fan control with binary signal, we can turn-on or turn-off it. It is a simple control signal when do not need different speeds. A relay can drive binary signal but for PWM signal we can not use relay as driver. The frequency of PWM is very high around $1 \mathrm{MHz}$ so relay switching speed can not satisfy it. Thus, high speed switches as the PWM driver are required.

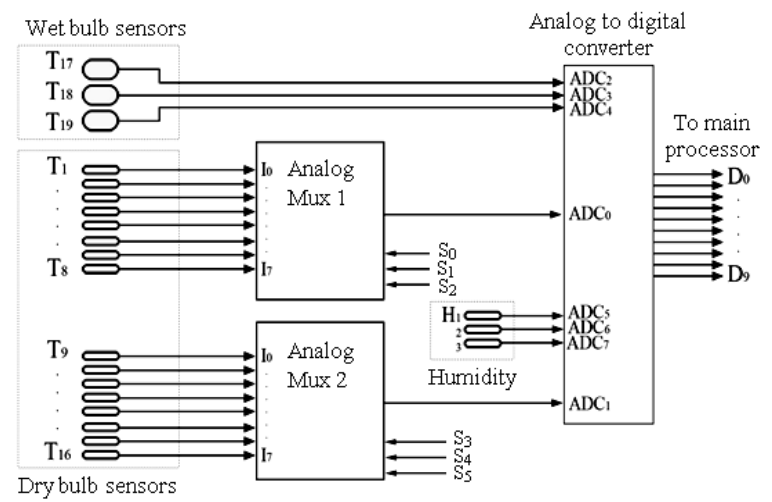

Fig. 4: Architecture of sensory system and its connections

Table 1: List of equipped instruments and type of controls

\begin{tabular}{lll}
\hline Output & Signal type & Driver \\
\hline Fan 1 & PWM & H-Bridge \\
Fan 2 & Binary & Relay \\
Heater 1 & PWM & H-Bridge \\
Heater 2 & Binary & Relay \\
Fan 3-5 & Binary & Relay \\
\hline
\end{tabular}


Am. J. Applied Sci., 7 (2): 160-166, 2010



Fig. 5: architecture of main controller unit

Employed processor has two individual PWM channels. Output level of PWM signal is controlled with an internal register variable. Therefore, using changes in register value and assuming new value in PWM register cause to change in fan speed or heather temperature.

Main controller: Each intelligent system uses a programmable controller as the main processor. Several types of processors are employed in industrial project which have own applications depending on their features. The PLC-based systems are reliable and common in industrial automation. Several companies produce PLC processors and their equipments such as drives, inputs and outputs. Microcontrollers are other low-cost processors which are utilized in many researches and projects. The PLC-based systems price are thousands time expensive than microcontrollerbased systems. A powerful yet cost-effective processor is required for the controller unit to provide a reliable system. The microcontrollers can be deployed as the main processors with good filtering circuits.

In proposed system, an ATMEGA-32 microcontroller is the main processor which whole system is controlled with. Figure 5 illustrates architecture of main controller unit.

External memories: To obtain good result and intelligent decision, previous status of system is an important parameter. Different decision approaches such as Fuzzy logic and neural network need recorded data to decide next status. Therefore, having a storage component to save all system events is required. Selected microcontroller has internal memory which is not enough to save whole system events. So, we used two external (Electrical Erasable Programmable Read Only Memory (EEPROM) modules to record all events and users' programs. One of modules is utilized to store previous values of sensors and system status in one period. The converted values of all sensors in time intervals are saved as a data base in EEPROM. Several control algorithms can analyze and employ these values.

Another memory module is used for saving users' settings and drying process tables which were discussed above. Users can inter their programs depend on inside materials and also they can save these programs for future use. Different functions such as edit, delete, define a new program, and comparing two or more programs are defined as main controller functions.

Host computer: Other feature of this system is having a communication with host PC. It will help us to remote trace drying process. A reliable serial interface using EIA-232 protocol helps to send online data simultaneously. These data can be used with engineering or analyzer software such as MATLAB or MINITAB. Also, for host PC a software based on LabVIEW was designed which allows to remote control system, change settings, define and read programs, record specified sensors' values, draw drying diagrams and its tables. This communication media helps to connect to machine from far distances using MODEM device. An external MODEM device and a telephone line are required to obtain a real-time connection to dryer and so the concurrent control will be achieved easily.

\section{RESULTS AND DISCUSSION}

The apples were dried at $75^{\circ} \mathrm{C}$ in the tray batch fruit dryer. The thickness of the measured samples was around $10 \mathrm{~mm}$ and the air velocity was $1.5 \mathrm{~m} \mathrm{sec}^{-1}$. The initial moisture content of the apples was $4 \pm 0.1 \mathrm{~kg}$ water $/ \mathrm{kg}$ dry matter and the equilibrium moisture content was approximately $0.06 \mathrm{~kg}$ water $/ \mathrm{kg}$ dry matter (these results were obtained were there was no more change in the weight). The moisture ratio versus drying time for apple at $75^{\circ} \mathrm{C}$ is shown in Fig. 6. The drying time to reach the equilibrium moisture content for the fresh apple slices were at over $300 \mathrm{~min}$ at $75^{\circ} \mathrm{C}$. The curve indicates that the moisture ratio decreases through the drying process furthermore analysis of the drying curves showed that there was no constant drying rate. Interestingly, to remove the last half of the moisture it took about two third of the whole drying process time. This can be due to reduce of speed in the diffusion process. The results were in agreement with other studies done on apple drying (Ramaswamy and Nieuwenhuijzen, 2002; Wang and Chao, 2002). 
Am. J. Applied Sci., 7 (2): 160-166, 2010

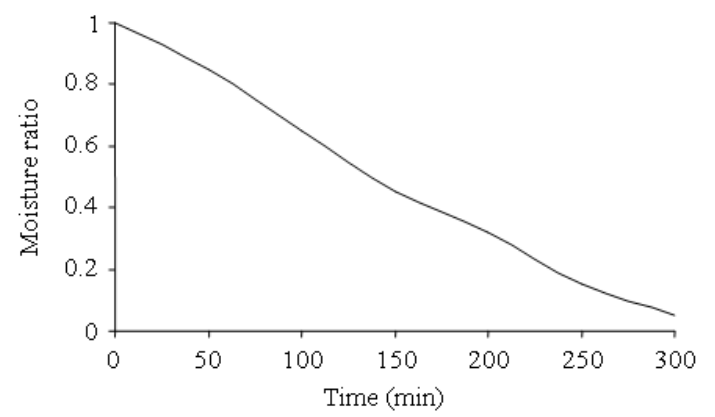

Fig. 6: Moisture profile of apple during drying at $75^{\circ} \mathrm{C}$ with air flow rate of $1.5 \mathrm{~m} \mathrm{sec}^{-1}$

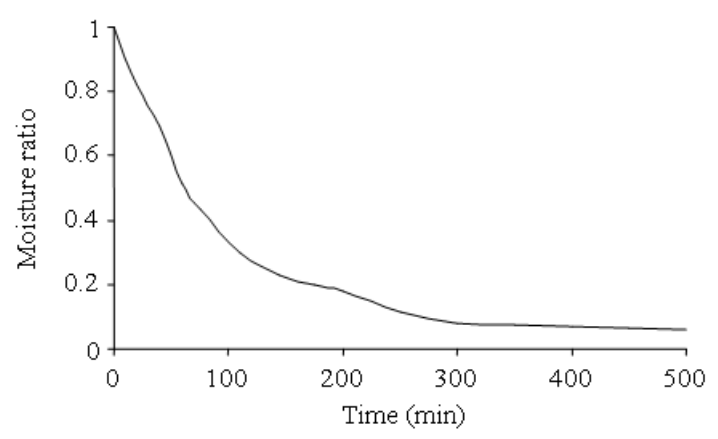

Fig. 7: Moisture profile of Banana during drying at $60^{\circ} \mathrm{C}$ and air flow rate at $0.7 \mathrm{~m} \mathrm{sec}^{-1}$

The experiment was conducted at $60^{\circ} \mathrm{C}$ and flow rate of $0.7 \mathrm{~m} \mathrm{sec}^{-1}$ to conduct the drying characteristics of banana figs. The thickness of the specimens was $35 \mathrm{~mm}$. The experiments were done to determine the equilibrium moisture content of banana. The results indicated that the moisture content of banana was around $80 \%$, this was measured by measuring the bone-dry mass which was approximately $20 \%$. The moisture ratio versus drying time for banana at $60^{\circ} \mathrm{C}$ is shown in Fig. 7. From the drying curves it is apparent that the moisture content ratio decreases continuously during the drying process moreover there is no constant drying rate period observed. The results are similar to other works done in banana drying (Maskan, 2000; Demirel and Turhan, 2003).

Plum drying is a very slow process due to the nature of the fruit which is covered with a waxy layer. In this experiments plums were subjected to $70^{\circ} \mathrm{C}$ temperature and flow rate of $1.2 \mathrm{~m} \mathrm{sec}^{-1}$ and the thickness of the specimen was about $3 \mathrm{~cm}$. Figure 8 gives the changes in moisture content of plums with time at $70^{\circ} \mathrm{C}$ and air velocity of $1.2 \mathrm{~m} \mathrm{sec}^{-1}$. The curves indicate that the moisture content decreases with the drying time additionally there was no constant rate period.

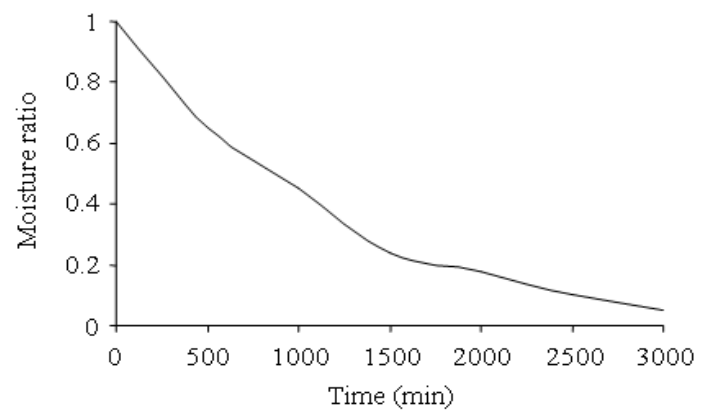

Fig. 8: Moisture profile of Plums drying at $70 \leqq \mathrm{C}$ and air flow rate at $1.2 \mathrm{~m} \mathrm{sec}^{-1}$

Drying time required for the samples was over 3000 min at $70^{\circ} \mathrm{C}$ to reach equilibrium moisture content. Similar results were found by other researchers such as (Cinquanta et al., 2002; Doymaz and Pala, 2002).

\section{CONCLUSION}

In this study a semi-industrial batch dryer machine was introduced. This machine was designed as a multi fruit dryer using user-friendly interface. Three types of fruit (banana, apple and plume) were selected and recorded results illustrate the flexibility of this machine as a batch fruit dryer. From the drying curves it can be revealed that drying occurs in the falling rate period for the selected fruits. After heating $75^{\circ} \mathrm{C}$ with an air flow rate of $1.5 \mathrm{~m} \mathrm{sec}^{-1}$ the apple slices dried over a $300 \mathrm{~min}$ period. For the case of banana, the temperature was set at $60^{\circ} \mathrm{C}$ and the air velocity was $0.7 \mathrm{~m} \mathrm{sec}^{-1}$ the drying duration was over $500 \mathrm{~min}$. In addition, for plums at $70^{\circ} \mathrm{C}$ and the drying air stream $1.2 \mathrm{~m} \mathrm{sec}^{-1}$, drying required was over $3000 \mathrm{~min}$. This difference is due to fruit properties for instance, size, initial moisture content, or the microstructure of the fruit tissue which governs the effective diffusion coefficient. Moreover, proposed system developed based on low-cost and lowpower consumption approaches. Microcontroller is the main processor of this system which makes suitable decision according to captured samples of environment with high-quality sensors. For the future research, we will utilize developed system as the dryer platform and we will work on various processing algorithms and system behaviors during a task.

\section{REFERENCES}

Barrett, D.M., L.P., Somogyi and H.S. Ramaswamy, 2005. Processing Fruits: Science and Technology. 2nd Edn., CRC Press, New York, ISBN: 0-84931478-X, pp: 841. 
Carsky, M., 2008. Design of a dryer for citrus peels. J. Food Eng., 87: 40-44. DOI: 10.1016/j.jfoodeng.2007.09.003

Ceylan, I., M. Aktas and H. Dogan, 2007. Mathematical modeling of drying characteristics of tropical fruits. Applied Therm. Eng., 27: 1931-1936. DOI: 10.1016/j.applthermaleng.2006.12.020

Chua, K.J. and S.K. Chou, 2003. Low-cost drying methods for developing countries. Trends Food Sci. Technol., 14: 519-528. DOI: 10.1016/j.tifs.2003.07.003

Cinquanta, L., M. DiMatteo and M. Esti, 2002. Physical pretreatment of plums Prunus domestica Part 2nd. Effect of the quality characteristics of different prune cultivars. J. Food Chem., 79: 233-238. DOI: 10.1016/S0308-8146(02)00138-3

Das, S., T. Das, P.S. Rao and R.K. Jain, 2001. Development of an air recirculating tray dryer for high moisture biological materials. J. Food Eng., 50: 223-227. DOI: 10.1016/S0260-8774(01)00024-3

Demirel, D. and M. Turhan, 2003. Air-drying behavior of dwarf Cavendish and gros Michel banana slices. J. Food Eng., 59: 1-11. DOI: 10.1016/S02608774(02)00423-5

Desmorieux, H., C. Diallo and Y. Coulibaly, 2008. Operation simulation of a convective and semiindustrial mango dryer. J. Food Eng., 89: 119-127. DOI: 10.1016/j.jfoodeng.2008.04.007

Doymaz, I. and M. Pala, 2002. The effects of dipping permanents on air-drying rates of the seedless grapes. J. Food Eng., 52: 413-417. DOI: 10.1016/S0260-8774(01)00133-9

Doymaz, I., 2004. Effect of dipping treatment on air drying of plums. J. Food Eng., 64: 465-470. DOI: 10.1016/ j.jfoodeng.2003.11.013

Erikson,R. W. and M. Dragan, 2001. Fundamentals of Power Electronics. 2nd Edn., Springer, London, ISBN: 0-7923-7270-0, pp: 883.

Ivanova, D. and K. Andonov, 2001. Analytical and experimental study of combined fruit and vegetable dryer. Energy Convers. Manage., 42: 975-983. DOI: 10.1016/S0196-8904(00)00108-4

Javanmard, M., K.A. Abbas and F. Arvin, 2009. A microcontroller-based monitoring system for batch tea dryer. J. Agric. Sci., 1: 101-106.

Karim, M.Z. and M.N.A. Hawlader, 2005. Drying characteristics of banana: Theoretical modeling and experimental validation. J. Food Eng., 70: 35-45. DOI: 10.1016/j.jfoodeng.2004.09.010
Kiranoudis, C.T., Z.B. Maroulis, D. Marinos-Kouris and M. Tsamparlis, 1997. Design of tray dryers for food dehydration. J. Food Eng., 32: 269-291. DOI: 10.1016/S0260-8774(97)00010-1

Lewicki, P.P. and E. Jakubczyk, 2004. Effect of hot air temperature on mechanical properties of dried apples. J. Food Eng., 64: 307-314. DOI: 10.1016/j.jfoodeng.2003.10.014

Lewicki, P.P., 2006. Design of hot air drying for better foods. Trends Food Sci. Technol., 17: 153-163. DOI: $10.1016 /$ j.tifs.2005.10.012

Maskan, M., 2000. Microwave/air and microwave finish drying of banana. J. Food Eng., 44: 71-78. DOI: 10.1016/S0260-8774(99)00167-3

Nijhuis, H.H., H.M. Torringa, S. Muresan, D. Yuksel, C. Leguijt and W. Kleok, 1998. Approaches to improving the quality of dried fruit and vegetables. Trends Food Sci. Technol., 9: 13-20. DOI: 10.1016/S0924-2244(97)00007-1

Ramaswamy, H.S. and N.H. van Nieuwenhuijzen, 2002. Evaluation and modeling of two-stage osmoconvective drying of apple slices. Dry. Technol., 20: 651-667. DOI: 10.1081/DRT-120002822

Soponronnsrit, S., A. Nathakaranakule, W. Limtrakool, S. Soponronnarit and W. Rakwichien, 1997. Banana fruit drying. RERIC Int. Energy J., 19: 55-62.

Teeboonma, U., J. Tiansuwan and S. Soponronnarit, 2002. Optimization of heat pump fruit dryers. J. Food Eng., 59: 369-377. DOI: 10.1016/S02608774 (02)00496-X

Umesh, H.H., K.H. Vishwanathan and M.N. Ramesh, 2004. Development of combined infrared and hot air dryer for vegetables. J. Food Eng., 65: 557-563. DOI: 10.1016/j.jfoodeng.2004.02.020

Valentine, R., 1998. Motor Control Electronics Handbook. 1st Edn., McGraw-Hill Professional, USA., ISBN: 0070668108, pp: 700.700.

Velic, D., M. Planinic, S. Tomas and M. Bilic, 2004. Influence of airflow velocity on kinetics of convection apple drying. J. Food Eng., 64: 97-102. DOI: 10.1016/j.jfoodeng.2003.09.016

Wang, J. and Y. Chao, 2002. Drying characteristics of irradiated apple slices. J. Food Eng., 52: 83-88. DOI: 10.1016/S0260-8774(01)00090-5

Wang, Z., J. Sun, X. Liaoa, F. Chenand and G. Zhao et al., 2007. Mathematical modeling on hot air drying of thin layer apple pomace. Food Res. Int., 40: 3946. DOI: 10.1016/j.foodres.2006.07.017 